DOI: https://doi.org/10.51431/bbf.v10i1.671

\title{
El deber de motivar las resoluciones judiciales en el estado constitucional
}

\author{
The duty to motivate decisions in the constitutional state
}

Máximo Villarreal Salomé

\begin{abstract}
RESUMEN
El presente artículo es uno de los resultados de la investigación "El Hábeas Corpus y la Exigencia de Constitucional de Motivar las Resoluciones Judiciales, Judiciales en el Distrito Judicial de Huaura", realizada en la Universidad Nacional de Barranca en el año 2018, en el que se investigó acerca del cumplimiento del deber que tienen los jueces de motivar las resoluciones judiciales al conocer las demandas de hábeas corpus. Objetivo: explicar sobre el cumplimiento del deber de motivación que tienen los jueces de fundamentar sus resoluciones, el cual constituye la piedra angular para la efectiva tutela de los derechos fundamentales en el Estado Constitucional. Método: Es descriptivo-explicativo, en el que se analizó 15 (quince) sentencias de hábeas corpus expedidos por los juzgados penal de Barranca, Huaura y Huaral. Resultado: En su mayoría las resoluciones judiciales en materia de hábeas corpus no están debidamente motivados. Conclusión: El deber de motivar las resoluciones judiciales en el Estado constitucional no se cumple en su integridad porque en el distrito judicial de Huaura, las demandas de hábeas corpus resueltos por los juzgados penales no cumplen con su deber de fundamentar sus decisiones.
\end{abstract}

Palabras clave: Deber, Motivación constitucional, Resolución judicial, Estado constitucional.

\section{ABSTRACT}

This article is one of the results of the investigation "Habeas Corpus and the Constitutional Requirement to Motivate Judicial and Judicial Resolutions in the Judicial District of Huaura", carried out at the National University of Barranca in 2018, in which It was investigated about the fulfillment of the duty that judges have to motivate judicial decisions. Objective: was to explain about the fulfillment of the duty of motivation that judges have to base their resolutions, which constitutes the cornerstone for the effective protection of fundamental rights in the Constitutional State. Method: used is descriptive-explanatory, in which 15 (fifteen) habeas corpus sentences issued by the criminal courts of Barranca, Huaura and Huaral were analyzed. Result: was that most of the court decisions on habeas corpus are not duly motivated. Conclusion: the duty to motivate judicial decisions in the constitutional State is not fully fulfilled, because in the Huaura Judicial District, habeas corpus claims resolved by criminal courts do not comply with their duty to substantiate their decisions.

Keywords: Duty, Constitutional motivation, Judicial resolution, Constitutional state

\section{INTRODUCCIÓN}

El fundamento racional del deber de motivación de las resoluciones judiciales se encuentra en el principio lógico-jurídico de razón suficiente, que actúa como la razón de toda explicación. Fue introducido por Leibniz en su Monadología en 1714, en el que estableció que "ningún hecho puede ser verdadero o existente y ninguna enunciación verdadera, sin que haya una razón suficiente para que sea así y no de otro modo". A partir de este planteamiento filosófico, el deber de motivación de resoluciones judiciales, ha sido como desarrollado y puesto en práctica por Arthur Schopenhauer, al que el filósofo peruano Mariano Ibérico, conceptualiza en su obra Principios de Lógica Jurídica, publicado en el año 1914, por la Facultad de Derecho de la Universidad Nacional San Marcos, como la guía de las leyes del pensamiento que sirven para alcanzar la verdad objetiva.

El principio filosófico señalado en el párrafo anterior, ha sido recogido por la disciplina del derecho con la denominación del deber de motivación de resoluciones judiciales, y que hoy está reconocido expresamente en las constituciones de países que cuentan con constituciones escritas. El deber de motivación que tienen los jueces sus resoluciones, es una conquista que la humanidad logró como consecuencia de las largas luchas y el esfuerzo por humanizar la administración de justicia. En el pasado, no existía el deber de motivación, las decisiones judiciales se dictaban sin demostrar razones. Cuando una causa llegaba a las manos del juez, este autoritativamente llamaba a las partes y sin más dictaba su sentencia sin motivar las razones de su decisión.

$$
\text { Recibido 17/01/2021 Aprobado 02/02/2021 }
$$

Este es un artículo de acceso abierto, distribuido bajo los términos de la Licencia Creative Commons Atribución 4.0 Internacional (http://creativecommons.org/licenses/by/4.0/)

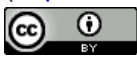

1'Doctor en Derecho. Profesor de la Facultad de Derecho y Ciencias Políticas de la Universidad Nacional José Faustino Sánchez Carrión, Huaura, Huacho, Lima , Perú. Universidad Nacional de Barranca, Barranca, Lima, Perú. Pertenece al Colegio de Abogado de Ancash. Email: mvillarreal@unjfsc.edu.pe 
La justificación de la investigación reside por ser un principio fundamental que está establecido en el artículo 139 inciso 5 de la Constitución, según el cual, es un deber del juez de motivar sus decisiones, so pretexto de ser declarado nulo he insubsistente. Hoy por hoy, el radio de acción de este principio constitucional se ha extendido, su aplicación y cumplimiento a todo órgano del poder del Estado.

Motivar una decisión judicial es producir razones. Es un trabajo que requiere esfuerzo intelectual y concentración, y es el instrumento con el que cuentan los jueces, tribunales y cortes constitucionales, y les sirve para comunicar a las partes intervinientes en el litigio, de hacerles conocer las razones de sus decisiones, para que a partir de ahí, puedan seguir el camino recorrido por el juez en su razonamiento, e incluso criticar o cuestionar la decisión.

Desde un punto de vista lingüístico, el lenguaje que se utiliza en la motivación, debe caracterizarse por su claridad, precisión y profundidad para que las partes en el litigio puedan comprender con facilidad el mensaje de la decisión judicial. El éxito o el fracaso de la motivación de las resoluciones judiciales depende del lenguaje empleado por el juez en la argumentación.

Una sentencia debe ser fundamentada con todos los elementos esenciales que respaldan la parte dispositiva. Para el juez esta es una tarea difícil. Y se complica aún más, además de tener que ser comprensible para el acusado, las víctimas y el público en general tiene que convencer al tribunal de alzada de que la decisión asumida es correcta. Esto significa que el juez tiene que esforzarse para que, la sentencia pueda ser comprendida sin problema. Si las partes no entienden la sentencia esto ocasiona que aumenten los recursos contra las decisiones judiciales y que éstas no encuentren credibilidad para ser aceptadas, todo lo cual afecta severamente la seguridad jurídica. (Schönbohm, 2014, p. 33).

Como dice Zavaleta, (2014). "La acertada comunicación de las decisiones judiciales en el Derecho es una cuestión fundamental para que la persona interactúe con racionalidad y eficacia en una determinada sociedad" ( $p$. 207). El problema de la administración de justicia en el Perú, es que el leguaje judicial utilizado por el juez en su mayoría no está dirigido para el ciudadano común, están llenos de tecnicismos que dificultan su comprensión. Cada órgano jurisdiccional fundamenta su decisión a su manera, muchas veces violando los cánones lógicos. Hay jueces que tienen el talento innato de saber argumentar racionalmente sus decisiones, pero la gran mayoría tienen serias deficiencias en el tema, y es ahí, en donde el Estado debe poner atención para dar alternativas de solución que puedan mejorar las deficiencias.

Sin embargo, en el Distrito Judicial de Huaura, el panorama no es positivo. Según los resultados de la investigación desarrollada, el deber de motivar las resoluciones judiciales solo se cumple de manera parcial y la consecuencia es la afectación directa a los derechos constitucionales.

\section{MATERIALES Y MEDIOS}

En la investigación desarrollada "El hábeas corpus y la exigencia constitucional de motivar las resoluciones judiciales en el distrito judicial de Huaura", la investigación que se desarrolló es el de tipo descriptivoexplicativo. La población en la investigación, fue las resoluciones de hábeas corpus emitidos en los años 2015,2017 y 2017 y la muestra fue en total quince sentencias emitidos en dicho periodo. La técnica que se utilizó es la técnica del análisis documental con su instrumento de guía de análisis documental. Las estadísticas de interpretación de medición se basaron en el número de demandas de hábeas corpus ingresados a la mesa de partes de la Corte Superior de Justicia de Huaura en los años 2015, 2016 y 2017.

Las resoluciones judiciales de hábeas corpus, se evaluaron teniendo en cuenta los siguientes criterios:

1. Evaluación de los errores de sintaxis, ortografía y redundancias.

2. Evaluación de la descripción clara de los hechos relevantes y la pretensión introducida por el demandante en la demanda.

3. Evaluación de la coherencia lógica (motivación interna) y solidez de la argumentación (motivación externa).

4. Evaluación de la fundamentación jurídica en el manejo de la jurisprudencia del Tribunal Constitucional peruano y la jurisprudencia internacional.

5. Identificar el sentido de las resoluciones judiciales de hábeas corpus (fundada o improcedente), emitidos por los juzgados penales (constitucionales).

Ahora bien, el grado de legitimidad social y el prestigio de los órganos jurisdiccionales, dependen de la calidad de sus decisiones que emiten, es por ello, que, en los países democráticos, motivar o fundamentar una resolución judicial es un derecho-deber, y es el instrumento más racional y objetivo para combatir la arbitrariedad en la administración de justicia.

El reflejo de este principio-derecho del deber de motivación de resoluciones judiciales es, que toda decisión debe provenir de la razón volente, y no de las pasiones o emociones subjetivas del juez, que lo único que conllevan es a la arbitrariedad.

En la vida real ¿qué significa motivar una resolución judicial y que función cumple? Olsen (1997) afirma: "son como los hitos que nos indican por donde ha seguido la ruta del pensamiento el juez. Son las estacas que evidencian la estructura de un complejo muy abstracto que demarcan la dirección de un camino, con todas sus ideas, rodeos y venidas hasta lograr la meta" $(p, 27)$. 
En el Perú, la motivación de la resolución judicial está establecido positivamente en artículo 139 inc. 5 la Constitución de 1993, en el Código Procesal Civil artículo 50 y en el Código Procesal Penal artículo 394.

Jurisprudencialmente, el concepto del deber de motivación de las resoluciones judiciales se ha ampliado, hoy por hoy, no se reduce solo al ámbito jurisdiccional, sino que se extiende a los procedimientos administrativos, parlamentarios, arbitrales, e incluso a los procedimientos suscitados entre privados.

En los procesos constitucionales y ordinarios, el deber constitucional de motivar de las decisiones jurisdiccionales, es una de los temas más invocados por las partes en litigio, ya sea porque la resolución judicial carece de sustento, o en algunas situaciones, por el simple hecho de no estar de conforme con la decisión.

El deber de motivar las resoluciones judiciales es un principio constitucional que obliga a los jueces a fundamentar sus decisiones, y a la vez, se configura como un derecho que tienen las partes en el litigio, de exigir a los jueces decisiones bien sustentadas tanto fáctico, jurídico y lógico.

El deber de motivar las resoluciones judiciales implica que el juez de la causa, debe justificarlo racionalmente tanto interna como externa. La racionalidad de la administración de justicia descansa en el principio de motivación de las resoluciones judiciales, funciona como una herramienta que sirve para evitar en lo posible la arbitrariedad dentro de la actividad jurisdiccional.

Una de las primeras condiciones de orden formal para que una decisión judicial esté correctamente motivado, debe caracterizarse por la claridad en los términos con el que son expresados en el desarrollo de la argumentación.

Una segunda condición de orden objetivo es que la decisión jurisdiccional este expuesto en armonía con los principios lógicos jurídicos (no contradicción, identidad, razón suficiente y el tercio excluido). Esto es, la coherencia en la exposición jurisdiccional, lo que implica que no exista contradicción (principio de no contradicción) en la argumentación expresada, además, que exista una correlación lógica en las razones que se invoca. Además, se exige que los fundamentos jurídicos y lógicos en sí, estén desarrollados en su plenitud (razón suficiente).

\section{RESULTADOS}

El resultado de la investigación fue fructífero. Se logró conseguir y estudiar los quince expedientes judiciales de hábeas corpus, en el cual se determinó que las resoluciones judiciales no están siendo motivados adecuadamente. A sí mismo, se logró describir las causas de la inadecuada motivación de las resoluciones judiciales en materia de hábeas corpus en el Distrito Judicial e Huaura.
En suma, los objetivos específicos propuestos en esta investigación se han logrado con éxito, producto del estudio de las quince resoluciones judiciales de hábeas corpus en el periodo de nuestra investigación. Se ha determinado los factores que inciden en la motivación inadecuada de las resoluciones juridiciales de hábeas corpus en las provincias de Huaura y Barranca.

Así mismo, se ha logrado describir las características del proceso judicial del hábeas corpus, los cuales son: es específico, porque está dirigido a la protección de la libertad individual y los derechos conexos establecidos en el art. 25 del Código Procesal Constitucional; es una acción pública, porque puede presentar la persona agraviada o cualquier persona; es informal, porque está desprovisto de cualquier formalidad; es preferente, porque pueden ser tramitado con urgencia por el juez; sumario, porque los plazos son breves y se caracterizan por su rapidez en la tramitación y operan de manera verbal.

En los juzgados penales de Huaura y Barranca del Distrito Judicial de Huaura, las resoluciones judiciales en materia de hábeas corpus no están siendo motivadas adecuadamente, lo que configura la afectación a los derechos fundamentales.

\section{DISCUSIÓN}

La discusión central respecto al deber de motivar las resoluciones judiciales es, si se debe positivizar una sola metodología a seguir o, si, por el contrario, se debe dejar a la libre discrecionalidad del juzgador la fundamentación de la decisión. La discusión sobre este punto sigue abierta en la teoría general del derecho y la filosofía jurídica.

El artículo 139 inciso 5 de la Constitución Política el Perú, solo se limita en reconocer el deber que tienen los jueces de motivar sus resoluciones judiciales, más no se pronuncia sobre la metodología para su aplicación tanto en la cuestión fáctica y formal. Lo mismo sucede en el derecho procesal peruano, las normas procesales (Código Procesal Penal y Código Procesal Civil), no desarrollan el procedimiento metodológico de cómo debe motivarse las resoluciones judiciales. La jurisprudencia del Tribunal Constitucional y de la Corte Suprema del Perú, guardan silencio al respecto, sólo se limitan en reconocer al deber de motivación de las resoluciones, como un derecho, principio o garantía fundamental del ciudadano.

Uno de los problemas principales que se presenta en la administración de justicia en el Perú, es por la falta o defectuosa motivación de las resoluciones judiciales, estas deficiencias se presentan precisamente porque los jueces en su gran mayoría no están formados ni capacitados en el mundo de la lógica jurídica, el cual es un limitante en el ejercicio de la función jurisdiccional que requiere con urgencia dar soluciones concretas y efectivas, a fin de lograr decisiones racionales, sólidas y objetivas. 


\section{CONCLUSIONES}

1. El deber de motivación de las resoluciones judiciales en el Estado constitucional, es un principioderecho, que no se reduce al ámbito estrictamente jurisdiccional, sino se extiende a los procedimientos administrativos, parlamentarios, arbitrales, e incluso a los procedimientos suscitados entre privados.

2. En el Distrito Judicial de Huaura, las demandas de hábeas corpus son resueltos por los juzgados penales, al no existir juzgados especializados en derecho constitucional, a sus labores propios que son conocer causas penales, se les adiciona competencias constitucionales entre ellos el hábeas corpus, el cual les dificulta resolver sus decisiones de manera oportuna.

3. En los juzgados penales de la provincia de Huaura y Barranca, en el periodo 2015, 2016 y 2017, las demandas de habeas corpus presentadas no son resueltos oportunamente, en los casos estudiados se observa que todos los hábeas corpus han sido resueltos fuera del plazo legal previsto, la normatividad referente a este tipo de proceso, señalado en la Constitución y en el Código Procesal Constitucional, no se cumple, es ineficaz, existe un trecho inmenso entre la normatividad y la realidad.

4. El resultado del estudio de los dieciséis expedientes judiciales de hábeas corpus en el periodo 2015, 2016 y 2017, demuestran que en la provincia de Huaura y Barranca que comprende el Distrito Judicial de Huaura, los juzgados penales no garantizan la efectiva protección de la libertad individual y los derechos conexos, al declarar infundadas en un $90 \%$ las demandas de hábeas corpus.

5. Las causas que inciden en la motivación inadecuada de las resoluciones judiciales son en primer lugar en el plano formal, por la utilización inadecuada de los adverbios y la ortografía. En segundo lugar, en cuanto a la estructura del fallo, en la parte introductoria de las sentencias, no se describen con claridad los hechos más relevantes y la pretensión introducida por el demandante. No se respeta la coherencia y el orden secuencial lógico de los hechos, de los fundamentos y la decisión. Solo un $40 \%$ cumplen con el estándar de motivación suficiente, mientras que el $60 \%$ tiene defectos en su fundamentación, lo que dificulta la comprensión jurídica del caso. En tercer lugar, en cuanto al manejo de la jurisprudencia del Tribunal Constitucional, es escasa, se ha detectado que en $60 \%$ de las resoluciones estudiadas hay citas irrelevantes e inadecuadas. En cuanto al manejo de la normatividad y la jurisprudencia internacional, no hay referencia o cita alguna, del cual se infiere que hay un desconocimiento notorio de la dogmática de los derechos fundamentales. En cuarto lugar, en el Distrito Judicial de Huaura, no hay juzgados constitucionales que puedan conocer los procesos constitucionales, el cual también constituye un limitante para los jueces penales, quienes se encargan de resolver problemas de índole constitucional.

6. El deber de motivar las resoluciones judiciales en el Estado Constitucional, no se cumple en su integridad. Sigue siendo un reto para el Estado peruano, perfeccionar el sistema de justicia a fin de que las decisiones de los órganos jurisdiccionales cumplan en su efectividad el deber constitucional de motivar las resoluciones judiciales.

\section{BIBLIOGRAFÍA}

SCHÖNBOHM, H. (2014). Manual de sentencias penales, aspectos generales de estructura, argumentación y valoración probatoria. Poder Judicial, Consejo Nacional de la Magistratura. Ara editores. Lima.

ZAVALETA, R. E. (2014). La Motivación de las resoluciones judiciales como argumentación jurídica. Grijley. Lima. 